\title{
La era del desarrollo sostenible: Nuestro futuro está en juego. Incorporemos el desarrollo sostenible a la agenda política mundial
}

\author{
Publicado por: Editorial PAIDÓS EMPRESA. 2016 \\ Elaborada por: Harold Banguero Lozano
}

Rec: Abril 2017

Acep: Octubre 2017

El autor presenta en este libro, de manera admirable y rigurosa, un diagnóstico completo sobre la situación actual del mundo en materia de desarrollo, al igual que propone acciones concretas y bien sustentadas para corregir los problemas generados por el modelo tradicional, reflejados en pobreza extrema, exclusión social e insostenibilidad ambiental. Para hacer frente a estos desafíos, propone impulsar a nivel mundial un modelo de desarrollo sostenible, fundamentado en el crecimiento económico para eliminar la pobreza extrema, la inversión social para lograr mayor inclusión social y la sostenibilidad ambiental para garantizar vida para esta y las futuras generaciones. Se resume a continuación la temática de sus catorce apasionantes capítulos.

En el capítulo uno define claramente lo que, en su opinión, es desarrollo sostenible y las razones por las cuales hay necesidad de lograrlo, que son, básicamente, por la persistencia de la pobreza en el mundo, la presencia de grandes grupos de población excluidos en una sociedad inequitativa y discriminatoria, y el deterioro ambiental causado por el crecimiento económico experimentado en los dos últimos siglos.

En el segundo capítulo presenta la situación del mundo en términos de desigualdad económica y social, diferenciales de ingreso, desigualdades campo-ciudad y entre grupos sociales, resaltando el hecho de que el modelo actual de desarrollo económico, en lugar de generar convergencia entre regiones, como teóricamente se esperaba, ha ampliado la brecha entre las ricas y las pobres, con una tendencia cada vez más divergente entre ellas.
En el capítulo tres revisa la historia del crecimiento económico mundial en los dos últimos siglos, destacando cómo el proceso, iniciado en Inglaterra con la Revolución Industrial, poco a poco se fue expandiendo a otros países de Europa, y posteriormente al resto del mundo, generando una dinámica de crecimiento económico sin precedentes. La globalización ha permitido que los avances tecnológicos estén hoy en día prácticamente al alcance de todas las naciones en el mundo. El costo de ello, sin duda, es el enorme deterioro ambiental causado por el uso cada vez más extensivo de los recursos naturales y la contaminación de los suelos, el agua y el aire.

En el capítulo cuatro el autor intenta una respuesta rigurosa y bien documentada a la pregunta sobre porqué algunos países se desarrollan mientras otros permanecen atrapados en la pobreza. Analiza factores relacionados con la geografía (transporte, energía, enfermedades y cosechas) y la cultura (demografía, educación y género y política). Sin ser exhaustivo, profundiza en aquellos que parecen más determinantes. Al final, sugiere políticas encaminadas a corregir esta divergencia.

En el quinto capítulo trata el tema de la pobreza extrema. Luego de la exposición de las razones por las cuales considera que es posible eliminarla en un horizonte de tiempo razonable, propone un conjunto de estrategias encaminadas a lograr este objetivo, entre las cuales se destaca la relacionada con un redireccionamiento de la ayuda externa, para solucionar los problemas de alimentación en países del África subsahariana y del Asia meridional. 
En el capítulo seis hace un intento de cuantificar los límites y la capacidad de carga del planeta tierra, teniendo en cuenta la dinámica del crecimiento de la población, la satisfacción de las necesidades de los menos favorecidos, la disponibilidad de los recursos energéticos y la producción mundial de alimentos. Al final concluye que el problema surge del modelo de crecimiento adoptado desde la Revolución Industrial, y muestra cómo es posible evitar una catástrofe si se toman a tiempo las decisiones políticas requeridas para hacer la transición hacia un modelo ambientalmente más sostenible.

En el capítulo siete aborda con propiedad el tema de la inclusión social y las desigualdades económicas y sociales de la población mundial. Analiza cómo, a pesar de los pactos y acuerdos logrados en las Naciones Unidas para garantizar igualdad de oportunidades para todos, la realidad muestra sociedades cada vez más divididas y grandes grupos de población discriminados por razones de género, etnia o religión.

En el capítulo ocho se presenta el tema de la educación, como una variable clave en el logro del desarrollo humano sostenible. Hace una reflexión sobre la educación a lo largo de todo el ciclo de vida, desde la primera infancia hasta el final de la vida, la rentabilidad económica y social de la misma, su papel en el logro de la movilidad social y la contribución de la educación superior al desarrollo tecnológico.

En el capítulo noveno, luego de hacer un diagnóstico sobre la situación de la salud en el mundo, hace recomendaciones para lograr cobertura sanitaria universal y la financiación de los servicios de atención primaria. Terminando, hace diez recomendaciones para universalizar la salud en los países pobres, en términos de saneamiento básico, prevención de la enfermedad y acceso a los servicios curativos.

En el capítulo diez se ocupa del tema de la seguridad alimentaria y sus implicaciones para la sostenibilidad ambiental. Plantea el dilema entre producir más alimentos para eliminar el hambre, y la sostenibilidad ambiental, amenazada por el uso indiscriminado de fertilizantes y pesticidas químicos. Considera que el problema nace en el modelo de producción agropecuaria elegido, y por lo tanto, la solución es hacer la transición hacia otro ambientalmente más sostenible y capaz de afrontar las consecuencias del cambio climático.
En el capítulo once se trata el tema de las ciudades resilientes. Analiza los patrones de urbanización en el mundo y sus implicaciones para la sostenibilidad ambiental. Destaca la importancia de la planificación urbana en el objetivo de lograr ciudades sostenibles, verdes y resilientes. Propone adoptar modelos de planificación estratégica desde el territorio, con el propósito de hacer compatibles los objetivos del desarrollo físico, económico y social de las ciudades con los de sostenibilidad ambiental.

En el capítulo doce aborda uno de los temas más controvertidos de la era actual, el cambio climático y sus implicaciones para el futuro de la humanidad. Luego de explicar de manera sencilla la ciencia básica del cambio climático y qué lo está generando, propone acciones para mitigarlo y para adaptarse a la nueva realidad. En este propósito juega un papel fundamental la puesta en marcha de la llamada revolución tecnológica sostenible. Al final, hace una reflexión sobre los obstáculos políticos que enfrentan las estrategias orientadas a reducir sus impactos en los años por venir.

En el capítulo trece trata el tema de la biodiversidad y la necesidad de proteger los ecosistemas. Partiendo de la definición de lo que ello significa, muestra la dimensión de esta amenaza y la necesidad de neutralizarla, con políticas relacionadas con reforestación, uso adecuado y descontaminación de las aguas afectadas por la presencia de mercurio y otros metales diluidos en ella. Considera que la protección de la diversidad bilógica, tanto de la flora como de la fauna, es imperativa para el mundo.

En el capítulo catorce hace una reflexión sobre los Objetivos del Desarrollo Sostenible (ODS), recientemente promulgados por la Organización de las Naciones Unidas (ONU), y las posibilidades de lograrlos en el horizonte de tiempo establecido. Considera que, si bien algunos de ellos no se lograrán totalmente, su importancia radica en fijarle al mundo objetivos y metas concretas en el propósito de lograr un desarrollo más sostenible y en su papel como guía para la asignación de los recursos que demanda. Para concluir, esboza los principios de la buena gobernanza, un tema que, quizás, requirió de mayor profundización en el libro, por ser la institucionalidad un factor clave en el logro de los objetivos del desarrollo sostenible propuesto. 
En síntesis, se trata de un libro que aborda de forma integral y rigurosa el tema del desarrollo sostenible, el desafío más grande que tiene la humanidad en el presente siglo. Se busca evitar la catástrofe haciendo la transición del actual modelo de desarrollo económico, social y ambientalmente insostenible, a otro que garantice vida y bienestar para esta y las futuras generaciones. Así, el profesor Sachs presen- ta en este libro no solo lo que hay que hacer, sino cómo hacerlo. La lectura es obligada para todos interesados en participar en este viaje de un mundo insostenible hacia otro más sostenible.

Espero que esta reseña haya creado en los lectores la suficiente motivación para leer el libro y actuar en consecuencia. 